\title{
1 Conceptual Problems with the DSM-IV Criteria for Posttraumatic Stress Disorder
}

\author{
RICHARD J. MCNALLY \\ Department of Psychology, Harvard University, USA
}

Controversy has haunted the diagnosis of posttraumatic stress disorder (PTSD) ever since its appearance in the third edition of the Diagnostic and Statistical Manual of Mental Disorders (DSM-III; American Psychiatric Association [APA], 1980). At the outset, psychiatrists opposed to the inclusion of the diagnosis in DSM-III argued that the problems of trauma-exposed people were already covered by combinations of existing diagnoses. Ratifying PTSD would merely entail cobbling together selected symptoms in people suffering from multiple disorders (e.g., phobias, depression, personality disorder) and then attributing these familiar problems to a traumatic event. Moreover, the very fact that the movement to include the diagnosis in DSM-III arose from Vietnam veterans' advocacy groups working with anti-war psychiatrists prompted concerns that PTSD was more of a political or social construct, rather than a medical disease discovered in nature. Although the aforementioned two concerns have again resurfaced in contemporary debates about PTSD, additional issues have arisen as well. For example, the concept of a traumatic stressor has broadened to such an extent that today the vast majority of American adults have been exposed to PTSD-qualifying events. This state of affairs is drastically different from the late 1970s and early 1980s when the concept of trauma was confined to catastrophic events falling outside the perimeter of everyday experience. As the chapters in this volume illustrate, early twenty-first-century scholars are raising fresh questions about the syndromic validity of PTSD.

Many traumatologists regard skepticism about the syndromic validity of PTSD as motivated by either a malicious agenda to silence the voices of survivors, or by sheer ignorance of the psychiatric consequences of overwhelmingly horrific experience. In contrast, scholars working outside mainstream traumatology do not consider the diagnosis as exempt from critique. They write from diverse perspectives, and hail from varied disciplines, such as anthropology (e.g., Antze \& Lambek, 1996; Young, 1995, 2001, 2002), sociology (e.g., Lembcke, 1998), history (e.g., Burkett, 2001; Burkett \& Whitley, 1998; Dean, 1997; Shephard, 2001, 2002), psychiatry (e.g., Bracken \& Petty, 1998; Reisner, 2003; Satel, 2003; Summerfield, 1999, 2000, 2001), and philosophy (e.g., Hacking, 1998, 1999, pp. 125-162). Rather than review these wide-ranging critiques of PTSD, this chapter focuses on several conceptual problems arising from the diagnostic criteria themselves. 
As previously observed, the diagnosis of PTSD emerged in the wake of the Vietnam War. Advocates for the diagnosis claimed that extant diagnostic categories failed to capture the unique psychiatric symptomatic profile arising from exposure to a catastrophic stressor. This profile, embodied in the criteria themselves, has evolved since DSM-III. According to DSM-IV (APA, 1994), PTSD is a syndrome comprising three clusters of signs and symptoms: (1) repeatedly reexperiencing the trauma (Criterion B: e.g., intrusive recollections of the event, nightmares); (2) avoidance of activities and stimuli associated with the trauma and emotional numbing (Criterion C: e.g., difficulty experiencing positive emotions); and (3) heightened arousal (Criterion D: e.g., irritability, exaggerated startle reflex). The disorder can only be diagnosed if a person has been exposed to an event that qualifies as a "traumatic" stressor (Criterion A). The symptoms must persist for at least one month (Criterion E) and must cause distress or impairment (Criterion F).

\section{CRITERION A: THE TRAUMATIC STRESSOR CRITERION}

PTSD is unusual among DSM-IV disorders in that its diagnosis requires a specific etiologic event: exposure to a traumatic stressor. If a person has not been exposed to a stressor that qualifies as "traumatic," then one cannot assign the diagnosis, regardless of how symptomatic the person might be. A great deal rides on how we define the concept of traumatic stressor, and how we distinguish traumatic stressors from the ordinary stressors of everyday life. The prevalence of the disorder, characterization of its psychobiological correlates, its assessment and treatment, all depend on how we define what counts as a traumatic stressor.

According to DSM-III (1980), a qualifying stressor was one "that would evoke significant symptoms of distress in almost everyone" (p. 238). Qualifying stressors, such as rape, combat, torture, and earthquakes, were those deemed to fall "generally outside the range of usual human experience" (APA, 1980, p. 236). The authors of DSM-III-R changed Criterion A (APA, 1987, p. 250). The concept of traumatic stressor now included witnessing or learning about one's family or friends being exposed to serious dangers as well as being directly exposed to such dangers oneself.

The DSM-IV PTSD Committee, on which this author was a member, debated the merits of further changes in Criterion A. Some members believed that an excessively stringent definition of what counts as a traumatic stressor would exclude many people from receiving the diagnosis and the treatment they deserve. If an event is subjectively perceived as traumatic, then would this not determine whether a person becomes symptomatic? Accordingly, some members believed that subjective appraisal ought to figure in the definition of what counts as a traumatic stressor.

The committee also discussed the possibility of abolishing Criterion A altogether. Removing reference to an etiologic event and diagnosing the disorder on the basis of signs and symptoms, as well as duration and impairment, would have brought PTSD in line with most other DSM syndromes that do not specify a causal event in the diagnostic criteria (e.g., panic disorder, obsessive-compulsive disorder).

Other committee members worried that either abolishing Criterion A or liberalizing the definition of a traumatic stressor would result in overdiagnosis of PTSD, thereby causing both scientific and forensic problems. Broadening the definition would make it difficult to 
specify the psychobiological mechanisms underlying symptoms arising from extremely diverse events. For example, attempts to elucidate the physiological correlates (e.g., heart rate, activation in specific brain regions) of recollecting a traumatic event would be difficult if definitional broadening resulted in highly heterogeneous groups of individuals being studied. The psychobiology of someone remembering a minor car accident will likely differ from someone remembering a brutal rape. Moreover, if any event could qualify as a PTSD-inducing stressor, as long as it was perceived as traumatic, then the diagnosis would invite abuse in the courtroom.

As it turns out, the committee did alter Criterion A (APA, 1994, pp. 427-428). Although a traumatic stressor had been defined as "an event that is outside the range of usual human experience" (DSM-III-R; APA, 1987, p. 250), this requirement was dropped in DSM-IV for two main reasons (Davidson \& Foa, 1991). First, it was unclear what constituted "usual" human experience. Stressors outside this boundary for an affluent American might well be within the boundary of usual experience for someone in an impoverished, wartorn country in the developing world. Second, many events triggering PTSD, such as automobile accidents and criminal assaults, were far from uncommon.

The DSM-IV committee changed the definition of Criterion A in other ways, too. A trauma-exposed person was now one who "experienced, witnessed, or was confronted with an event or events that involved actual or threatened death or serious injury, or a threat to the physical integrity of self or others," as long as "the person's response involved intense fear, helplessness, or horror."

This two-part definition of a traumatic stressor warrants several comments. First, the concept of a traumatic stressor was no longer defined solely by criteria external to the person. Indeed, the event now was defined partly by the emotional response of the person. Second, like DSM-III-R, witnessing or learning about another's misfortune counted as a trauma for the witness or recipient of this information. But the DSM-IV criteria no longer required that the direct victim be among the family or friends of the witness. Third, "threats to the physical integrity of self" (p. 427) allowed "developmentally inappropriate sexual experiences without threatened or actual violence or injury" (p. 424) to count as traumatic stressors. This revision enabled nonviolent childhood sexual molestation to qualify as a PTSD-level stressor. Fourth, if a person failed to experience intense fear, helplessness, or horror peritraumatically (i.e., during the trauma), then the diagnosis could not be applied. This stipulation would seemingly bar anyone who "dissociated" during the trauma from receiving the diagnosis. Dissociation supposedly blunts the emotional response to trauma. Yet scholars have adduced evidence that peritraumatic dissociation is among the best predictors of subsequent PTSD (Ozer, Best, Lipsey, \& Weiss, 2003).

\section{CONCEPTUAL BRACKET CREEP IN THE DEFINITION OF TRAUMA}

DSM-IV introduced changes in Criterion A that have accelerated a conceptual bracket creep in the definition of trauma (McNally, 2003a). Despite a textual emphasis on perception of serious physical threat, these changes have broadened what counts as a PTSDlevel stressor. For example, a person who reacts with horror upon learning about another person's exposure to a threat would qualify as having been exposed to a Criterion A traumatic stressor. That is, one no longer need directly be exposed to life threat, nor even 
vicariously exposed to danger. To qualify as a trauma survivor, one need only respond with fright to learning about the misfortunes of others, including strangers.

Breslau and Kessler (2001) conducted an important empirical study documenting how conceptual bracket creep in the definition of trauma has altered the epidemiologic profile of PTSD. By applying the DSM-IV stressor criterion, they found that $89.6 \%$ of adults in the Detroit metropolitan area had been exposed to at least one traumatic event-yet only 9.2\% developed PTSD. Breslau and Kessler found that the rate of exposure to traumatic stressors increased from 270 events per 100 persons to 430 events per 100 persons. That is, "the population's total life experiences that can be used to diagnose PTSD has increased materially by 59.2\%" (Breslau \& Kessler, 2001, p. 703). Events now qualifying as traumatic under the broadened stressor criterion accounted for $37.8 \%$ of the total number of cases of PTSD identified in the community.

Attending closely to the details of DSM-IV, Avina and O'Donohue (2002) argued that repeatedly overhearing off-color jokes in the workplace may qualify, under some circumstances, as a Criterion A stressor sufficiently traumatic to produce PTSD. More specifically, exposure to sexual jokes and other, more severe forms of sexual harassment may provide the basis for lawsuits to obtain "appropriate monetary compensation" (Avina \& O’Donohue, 2002, p. 74) for work-related PTSD.

Although Avina and O'Donohue (2002) were merely presenting the theoretical and clinical rationale for suing employers who permit employees to tell offensive sexual jokes, others have confirmed that such successful suits have begun to occur. For example, a Michigan woman filed suit against her employer after claiming she developed PTSD from repeatedly hearing foul language and being exposed in the workplace to practical jokes having sexual connotations (McDonald, 2003). To compensate her for PTSD and claims of depression, the court awarded \$21 million.

The expanding definition of trauma is relevant to surveys conducted after the September 11, 2001, terrorist attacks. For example, a person horrified by watching television footage of the carnage at the World Trade Center would qualify as having been exposed to a Criterion A stressor (e.g., being "confronted with" an event that threatened others), thereby enabling the classification of any reactions (e.g., dreams, sleep problems, irritability) as "symptoms" of PTSD. Consider the RAND Corporation study. Telephone interviewers assessed a representative sample of 560 adults throughout the United States on the weekend after 9-11, concluding that $44 \%$ of Americans "had substantial symptoms of stress" (Schuster et al., 2001, p. 1507), and ominously predicting that the psychiatric effects of terrorism "are unlikely to disappear soon" (p. 1511). Schuster et al. (2001) said that "clinicians should anticipate that even people far from the attacks will have traumarelated symptoms" (p. 1512).

How did Schuster et al. arrive at these dire conclusions? Interviewers asked respondents whether they had experienced any of five symptoms since the attacks on September 11, with each symptom rated on a five-point scale ranging from one ("not at all") to five ("extremely"). A respondent qualified as "substantially stressed" if he or she assigned a rating of at least four ("quite a bit") to one of the five symptoms. Thus, respondents who said they had experienced "quite a bit" of anger at Osama bin Laden were classified as substantially stressed.

Several authors have expressed concerns about the medicalizing of these emotional reactions by calling them symptoms reflective of presumed psychiatric illness (e.g., 
Reisner, 2003; Wakefield \& Spitzer, 2002). Moreover, many of the "symptoms" of PTSD may reflect nonspecific distress. Consider a New Yorker who was working downtown on 9-11, and who later mentions problems with falling asleep, difficulty concentrating, and irritability. Although each of these might be a "PTSD symptom," each may arise for unrelated reasons. Similarly, it would be misleading to refer to nonspecific physical symptoms, such as fatigue and cough, as "symptoms" of bacterial pneumonia in the absence of verifying evidence (e.g., a culture; McNally, Bryant, \& Ehlers, 2003).

\section{CRITERION A AND THE CENTRAL PARADOX OF PTSD}

The central paradox of PTSD is that psychologically traumatizing events - as distinct from physically traumatizing ones - must be cognitively appraised for their impact to be felt. A force delivered to the skull can damage the brain irrespective of one's appraisal of the experience. But a psychic trauma carries its force through the meaning the event has for the person. For example, a person threatened with a gun can only be psychically traumatized if he or she knows what a gun is.

In fact, the proximal cause of PTSD may be how the person interprets the meaning of the stressor (McNally, 2003b, pp. 96-100). And how one interprets the event may, in turn, be influenced by historical and cultural factors. For example, although witnessing the violent death of another person is currently deemed a Criterion A stressor, attending public executions has often been a popular form of family entertainment throughout history (Domino \& Boccaccini, 2000). Shocking nearly everyone in the West, many African girls eagerly await traditional coming-of-age ceremonies in which their genitalia are carved up by older women (Obermeyer, 1999; Shweder, 2000). Conversely, compelling Hindus to violate religious taboos by forcing them to eat pork and beef is a common method of torture in Bhutan (Shrestha et al., 1998).

If subjective appraisal of the event is the proximal determinant of its stressfulness, does this imply that whatever a person regards as highly threatening or stressful counts as a traumatic event? Is conceptual bracket creep inevitable?

Not necessarily. Merely because all psychological stressors are cognitively mediated does not entail that reality does not constrain appraisal. Indeed, stressors that are appraised as highly threatening are often highly threatening. Problems arise only when seemingly trivial stressors are appraised as highly traumatic (e.g., repeatedly overhearing foul language in the workplace). When appraisal closely tracks reality, it becomes redundant with objective features of the event. When appraisal overestimates threat, vulnerability factors are likely to account for more of the variance than properties of the event itself. If PTSD is to remain in DSM-V, then it might be wise to tighten up the definition and conceptual underpinnings of criterion $\mathrm{A}$.

\section{CRITERION A AND THE DOSE-RESPONSE MODEL}

The dose-response model of PTSD holds that symptom severity increases as the magnitude of the stressor increases (March, 1993). Many scientists interpret this model in Pavlovian fear conditioning terms (e.g., Keane, Zimering, \& Caddell, 1985). They regard traumatic stressors as akin to unconditioned stimuli that evoke unconditioned responses of terror, thereby establishing neutral cues as conditioned stimuli that elicit the conditioned responses integral to PTSD. Therefore, they hold that a laboratory rat's response to 
inescapable shock mimics at least some aspects of the human response to trauma (Foa, Zinbarg, \& Rothbaum, 1992; van der Kolk, Greenberg, Boyd, \& Krystal, 1985). Within limits, the dose-response model has its merits. All things being equal, extreme stressors are more likely to produce PTSD symptoms than are mild stressors. Yet many studies fail to support a straightforward dose-response relation between measures of trauma severity and resultant psychopathology.

The dose-response construal of PTSD suffers from conceptual as well as empirical problems. For example, calibrating stressor magnitude is much more complicated in traumatology than it is in the Pavlovian conditioning laboratory. Scientists can measure laboratory stressors (unconditioned stimuli) in purely physical terms that are independent of the rat's behavior (e.g., number of shocks, shock amperage). Yet in traumatology, scientists often must rely solely on the retrospective self-reports of trauma victims themselves for measuring stressor magnitude. That is, researchers presuppose that psychiatrically disturbed persons can provide reliable, objective accounts of stressor magnitude undistorted by their clinical state.

In striking contrast to this presupposition, several longitudinal studies have shown that current clinical state affects how trauma-exposed people remember both the objective (e.g., exposure to danger) and subjective (e.g., one's emotional reaction to danger) features of past trauma events (Harvey \& Bryant, 2000; Roemer, Litz, Orsillo, Ehlich, \& Friedman, 1998; Schwarz, Kowalski, \& McNally, 1993; Southwick, Morgan, Nicolaou, \& Charney, 1997). The more distressed a survivor is at follow-up assessment, the more severe the survivor recalls the original traumatic stressor to have been, relative to the original assessment. Because so many studies consistent with the dose-response model depend on a correlation between current self-reported symptoms and self-reported recollection of traumatic stressors (e.g., Friedman, Schneiderman, West, \& Corson, 1986), one must question how strong the relation really is between objectively defined stressors and resultant psychopathology.

\section{PROBLEMS WITH THE SYMPTOMATIC CRITERIA}

Although many of the most contentious issues regarding PTSD concern DSM-IV's Criterion A, specific difficulties with several symptomatic criteria have become apparent. Consider the reexperiencing symptoms (Criterion B), in which remembering the trauma as if it were occurring in the present is the hallmark of PTSD. The focus on past threat is what sets PTSD apart from the other anxiety disorders, in which threat lies in the future (e.g., generalized anxiety disorder, panic disorder).

The reexperiencing cluster comprises five items (APA, 1994, p. 428): (1) "recurrent and intrusive distressing recollections of the event, including images, thoughts, or perceptions;" (2) "recurrent distressing dreams of the events;" (3) "acting or feeling as if the traumatic event were recurring," including illusions, hallucinations, flashbacks, and a sense of reliving the experience; (4) "intense psychological distress at exposure to internal or external cues that symbolize or resemble an aspect of the traumatic event;" and (5) "physiological reactivity on exposure to internal or external cues that symbolize or resemble an aspect of the traumatic event."

There is surprisingly little prospective data on these symptoms. Most of what we know 
about intrusive recollections and nightmares, for example, is based on asking patients to think back and reflect on the frequency of intrusive thoughts and nightmares (for a review, see McNally, 2003b, pp. 105-124). Researchers have almost never had patients track the frequency of these symptoms in structured diaries. Asking patients to estimate how often they have suffered from intrusive thoughts, nightmares, and flashbacks during the past month - let alone, say, since the Vietnam War-amounts to relying heavily on fallible autobiographical memory.

Retrospective accounts of reexperiencing symptoms can produce misleading results. For example, van der Kolk, Blitz, Burr, Sherry, and Hartmann (1984) popularized the notion that traumatic nightmares are often exact replicas - instant replays — of the sensory aspects of traumatic experiences. But as Brenneis (1994) pointed out, van der Kolk et al. "based their 'exact replica' conclusion on the dreamers' statements of equivalence without collecting any dreams" (p. 432). Instead of having patients prospectively record their nightmares in a dream diary shortly after awakening, van der Kolk et al. simply asked their PTSD patients during an interview whether their nightmares matched the combat events the patients had experienced in Vietnam.

Mellman and his colleagues have been among the few investigators who have asked trauma patients to record their reexperiencing symptoms (nightmares) prospectively (Esposito, Benitez, Barza, \& Mellman, 1999; Mellman, David, Bustamante, Torres, \& Fins, 2001). They found that many of the recorded distressing dreams were related to trauma, and a minority were experienced as replicas of the trauma.

Yet nightmares cannot literally replay the sensory aspects of the traumatic experience. An instant replay would require a quasi-photographic mechanism that accurately preserves the sensory details of the trauma on a mental videotape that gets replayed during sleep. But because autobiographical memory does not operate like a video recorder during waking life, there is no reason to expect it does so during sleep. Moreover, to claim that a nightmare is an exact replica of a traumatic event, the person must compare the nightmare, recollected after awakening, to the trauma as recollected during ordinary waking life. But the standard against which the dream is compared-the trauma as recalled by the dreamer when awake-is itself a fallible reconstruction of the event. Because the standard of comparison is itself a reconstruction, how can anyone be sure that the dream replicates what actually happened? Although the occasional "replicative" nightmare is a striking feature of psychological trauma, it is nothing more than a memory illusion.

Inspection of the reexperiencing criteria raises other questions. Each of the five criteria supposedly picks out a distinct mode of reexperiencing the trauma. But how distinct are these phenomena? Symptom B1 includes "images" and "perceptions" of the event in addition to "thoughts" about it. How is an "image" or a "perception" distinguishable from the "hallucination" or "flashbacks" listed under symptom B3? Are flashbacks merely especially vivid images or perceptions (or thoughts)? Although Brewin (2001) has suggested that flashbacks may be mediated by neurobiological mechanisms distinct from those mediating intrusive thoughts, his theory awaits further empirical scrutiny.

Historians have recently adduced evidence seemingly inconsistent with Brewin's theory about a special mechanism subserving flashbacks (Jones et al., 2003). Scrutinizing British medical military archives, they found that psychiatrically traumatized soldiers in World War I and World War II almost never reported anything akin to the flashback experiences mentioned by trauma survivors much later in the twentieth century. If the flashback 
amounts to an idiom of distress bound to a certain cultural and historical niche, then one must question whether an evolved neurobiological system mediating a timeless, acultural response to trauma truly exists.

In fact, Frankel's (1994) historical survey of the flashback experience suggests that it is anything but a timeless response to trauma. The concept originated in the motion picture industry, migrated to psychiatry as a term referring to the reactivation of sensory disturbances in hallucinogenic drug users, and finally emerged in traumatology to denote an especially vivid form of reliving traumatic experiences in Vietnam veterans (Frankel, 1994).

On the other hand, Kardiner (1941) described cases of American World War I veterans who reported symptoms strikingly similar to later descriptions of flashbacks (p. 82). Kardiner's cases raise the possibility that the scrutinizing of British military archives by Jones et al. (2003) only demonstrated that British doctors simply failed to ask the right questions of their patients, thus leading to the near-absence of flashbacks from the military medical records (Jones et al., 2003; see also Kimbrell, Myers, \& Freeman, 2003).

One thing is certainly clear. For reasons sketched above, flashbacks cannot literally be a replaying of the sensory events that occurred during the trauma. The mind does not operate like a videotape machine, regardless of how compelling these sensory reenactments seem to be. In fact, like vivid "flashbulb memories" (Brown \& Kulik, 1977), flashbacks often depart from what the patient knows actually happened (McNally, 2003b, pp. 53-57, 113-117). For example, Mayer and Pope (1997) described a Vietnam veteran whose flashbacks of his combat injury differed from the way he knew it had actually occurred. People have reported flashbacks of the homicide of loved ones even though they were not present at the murder scene (Rynearson \& McCreery, 1993). And vivid obsessional images have been mistaken for flashbacks (Lipinski \& Pope, 1994).

Among the reexperiencing symptoms, psychophysiologic reactivity to reminders of the trauma have been extensively studied in the laboratory. Depending on one's criteria, between $50 \%$ and $67 \%$ of people with PTSD exhibit heightened physiological reactivity (e.g., skin conductance, heart rate) while listening to audiotaped descriptions of their traumatic event (Orr, Metzger, \& Pitman, 2002). Trauma-exposed people without PTSD are seldom physiologically reactive while listening to audiotaped descriptions of their traumatic experiences. Still, many people who qualify for PTSD according to structured diagnostic interviews are nonreactive for reasons that are not fully understood. Finally, complicating matters somewhat, nonpsychotic people who believe they have been abducted by space aliens also exhibit heightened reactivity to audiotaped descriptions of their traumatic "abduction memories" (McNally et al., in press). Taken together, psychophysiologic reactivity in the script-driven imagery paradigm reflects emotional intensity of a memory, regardless of whether it is accurate or not.

Problems with symptomatic criteria are not confined to the reexperiencing cluster. Indeed, probably no PTSD symptom has caused as much confusion or mischief as that of "psychogenic amnesia" (McNally, 2004). The original conception of PTSD emphasized that traumatic experiences were all too memorable, an assertion fully consistent with the scientific literature (Pope, Oliva, \& Hudson, 1999). DSM-III (1980) did acknowledge that memory trauma survivors complain about ordinary forgetfulness in everyday life, as embodied in the symptom of "memory impairment or trouble concentrating" (p. 238). Contrary to the misconceptions of some psychotherapists (e.g., Brown, Scheflin, \& Whitfield, 
1999), this symptom has nothing whatsoever to do with "repressed" memories of trauma, a concept that refers to an inability to access dissociated traumatic experiences. Such authors confuse everyday forgetfulness occurring after a trauma with an inability to remember the trauma itself.

As reports of repressed (or dissociated) and recovered memories of trauma began to gain currency among some therapists in the 1980s, certain traumatologists reconceptualized PTSD as entailing an inability to remember trauma (or least parts of it) as well as a syndrome marked by intrusive remembering. This view was incorporated in DSMIII-R, and retained in DSM-IV, whereby everyday forgetfulness was quietly replaced by a new symptom: an "inability to recall an important aspect of the trauma (psychogenic amnesia)" (p. 250).

The meaning of this symptom is ambiguous. Inferences about amnesia, or an inability to remember, presuppose that the information got encoded in the first place. Yet this is often not true. Because the mind is not a video recorder, not every aspect of a traumatic experience will get encoded into memory: this is especially true when an event is rapidly unfolding as in an automobile accident or a sudden assault. Accordingly, failure to encode every aspect of a traumatic experience-including an "important" one-must not be confused with an inability to recall an aspect that has been encoded. As another example, many people robbed at gunpoint fail to encode the face of their assailant because their attention was focused on the assailant's weapon. Their inability to recall what the robber looked like does not count as amnesia because the face of the robber never made it into long-term memory. The DSM-V Committee should seriously consider replacing this criterion with the original DSM-III symptom of memory and concentration problems.

\section{WHATEVER HAPPENED TO DELAYED ONSET PTSD?}

Despite its reputation as a uniquely traumatizing conflict, the Vietnam War was notable for its low rate of psychiatric casualties (Dean, 1997, p. 40). The rate of psychiatric breakdown was 12 per 1,000 men, whereas it was 37 per 1,000 during the Korean War, and as high as 101 per 1,000 during World War II. Moreover, most of the psychiatric cases in Vietnam were unrelated to combat trauma.

Not only was the rate of breakdown rare in-country, research on those returning to the United States also failed to uncover much psychopathology. In a seldom-cited prospective study of 577 returning combat veterans, assessed seven months after their return from Vietnam, Borus (1974) found no significant difference in indices of maladjustment relative to a control group of 172 non-veterans. Indeed, only $1.1 \%$ (6 out of 577) of the combat veterans experienced adjustment problems, including either psychiatric or antisocial, that warranted a premature discharge from the military. Yet anti-war psychiatrists, such as Lifton (1973), claimed that the effects of the war emerged only months or years after the combatant returned from the service. Indeed, the main argument for the inclusion of PTSD in DSM-III was that the syndrome typically emerged long after the trauma (Scott, 1993, p. 43).

Strikingly, however, the syndrome of delayed onset PTSD has nearly vanished from the psychiatric landscape. Studies on trauma survivors since 1980 have overwhelmingly indicated that people who develop PTSD exhibit their symptoms within hours or days after the trauma-not years later (e.g., Rothbaum \& Foa, 1993). Indeed, the realization 
that PTSD symptoms, if they occur at all, erupt immediately following exposure to trauma was an important reason for including acute stress disorder in DSM-IV. Almost all cases of apparent delayed onset PTSD turn out to involve either delayed help-seeking or subsyndromic PTSD intensified by exposure to another stressor (Solomon, Kotler, Shalev, \& Lin, 1989). Pure cases of delayed onset—exposure to trauma followed by a long period of good adjustment that precedes full-blown emergence of the disorder-are rare to nonexistent.

Delayed onset PTSD remains on the books as a relic from the Vietnam era (APA, 1994, p. 429). It may constitute an instance of a "transient mental illness" (Hacking, 1998) - a psychiatric disease that flourishes in a certain cultural and historical niche, and then later disappears when circumstances change.

\section{CONCLUSION}

For a PTSD diagnosis, DSM-IV requires that symptoms be present for at least one month (Criterion E) and produce impairment or distress (Criterion F). These criteria reflect an oblique attempt to demarcate "normal" stress reactions from "disordered" ones. Attempts to mark a distinction between genuine mental disorders and ordinary unhappiness is a vexing conceptual problem for psychopathology in general, not just traumatology (e.g., Lilienfeld \& Marino, 1995; McNally, 2001; Wakefield, 1992).

Advocates of the PTSD diagnosis seem to believe that it constitutes a natural kind, not a culture-bound, socially constructed idiom of distress. Natural kinds are entities discovered in nature that exist independently of our attempts to describe them (see Dupré, 2002; Wilson, 1999). For example, scientists believe that any successful chemistry would ultimately result in discovery of the same elements represented in the periodic table. The elements were there to be discovered by chemists; they were not invented or constructed by them. Likewise, medical scientists discover diseases, such as AIDS, cancer, and bacterial pneumonia. These are natural kinds, not socially constructed kinds. With the increasing medicalization of psychopathology, advocates for the reality of a PTSD diagnosis often claim biological support for the syndrome as a natural kind. As Yehuda and McFarlane (1997) argued:

biological findings have provided objective validation that PTSD is more than a politically or socially motivated conceptualization of human suffering. Indeed, biological observations have delineated PTSD from other psychiatric disorders and have allowed a more sophisticated description of the long-term consequences of traumatic stress. (p. xi)

Yehuda and McFarlane (1997) further argue that biological data provide

concrete validation of human suffering and a legitimacy that does not depend on arbitrary social and political forces. Establishing that there is a biological basis for psychological trauma is an essential first step in allowing the permanent validation of human suffering. (p. xv)

Although one might take issue with the claim that acknowledgment of human suffering requires the results of biological validation, Yehuda and McFarlane apparently believe that researchers in traumatic stress have managed to "carve nature at its joints" by discover- 
ing a discrete syndrome that differs in kind, not merely in degree, from the normal stress response. That is, they appear to suggest that PTSD was discovered in nature by astute clinical scientists; it was not created by them.

Yet it is likely that PTSD is neither a natural kind nor a purely socially constructed kind. There is a third possibility. PTSD may count as an interactive kind (Hacking, 1999, pp. 100-124). Unlike natural kinds discovered in nature, interactive kinds are affected by the very process of classification itself. For example, given that flashbacks are now part of the cultural lore of trauma, people experience their trauma as photographic reenactments, whereas this would not have been possible before. Thus, according to this perspective, PTSD is not "discovered" in nature, but co-created via the interaction of psychobiology and the cultural context of classification.

In conclusion, despite nearly 25 years of research, the PTSD diagnosis remains contentious (McNally, 2003a). Many, if not most, traumatologists believe that PTSD is a timeless, acultural psychobiological response to overwhelming trauma-a natural kind. One purpose of this chapter, and other contributions to this text, is to encourage scholars and clinicians to revisit their assumptions and to reexamine them with an open mind.

\section{REFERENCES}

American Psychiatric Association (1980). Diagnostic and statistical manual of mental disorders (3rd edn). Washington, DC: Author.

American Psychiatric Association (1987). Diagnostic and statistical manual of mental disorders (3rd edn, rev.). Washington, DC: Author.

American Psychiatric Association (1994). Diagnostic and statistical manual of mental disorders (4th edn). Washington, DC: American Psychiatric Association.

Antze, P., \& Lambek, M. (eds) (1996). Tense past: Cultural essays in trauma and memory. New York: Routledge.

Avina, C., \& O'Donohue, W. (2002). Sexual harassment and PTSD: Is sexual harassment diagnosable trauma? Journal of Traumatic Stress, 15, 69-75.

Borus, J. F. (1974). Incidence of maladjustment in Vietnam returnees. Archives of General Psychiatry, 30, 554-557.

Bowman, M. (1997). Individual differences in posttraumatic response: Problems with the adversitydistress connection. Mahwah, NJ: Erlbaum.

Bowman, M. (1999). Individual differences in posttraumatic distress: Problems with the DSM-IV model. Canadian Journal of Psychiatry, 44, 21-33.

Bracken, P. J., \& Petty, C. (eds) (1998). Rethinking the trauma of war. London: Free Association Books.

Brenneis, C. B. (1994). Can early childhood trauma be reconstructed from dreams? On the relation of dreams to trauma. Psychoanalytic Psychology, 11, 429-447.

Breslau, N., \& Kessler, R. C. (2001). The stressor criterion in DSM-IV posttraumatic stress disorder: An empirical investigation. Biological Psychiatry, 50, 699-704.

Brewin, C. R. (2001). A cognitive neuroscience account of posttraumatic stress disorder and its treatment. Behaviour Research and Therapy, 39, 373-393.

Brown, D., Scheflin, A. W., \& Whitfield, C. L. (1999). Recovered memories: The current weight of the evidence in science and in the courts. Journal of Psychiatry and Law, 27, 5-156.

Brown, R., \& Kulik, J. (1977). Flashbulb memories. Cognition, 5, 73-99. 
Burkett, B. G. (2001). Stolen valor: The "history" that never was. In J. N. Moore \& R. F. Turner (eds), The real lessons of the Vietnam War: Reflections twenty-five years after the fall of Saigon (pp. 249-265). Durham, NC: Carolina Academic Press.

Burkett, B. G., \& Whitley, G. (1998). Stolen valor: How the Vietnam generation was robbed of its heroes and its history. Dallas, TX: Verity.

Davidson, J. R. T., \& Foa, E. B. (1991). Diagnostic issues in posttraumatic stress disorder: Considerations for the DSM-IV. Journal of Abnormal Psychology, 100, 346-355.

Dean, E. T., Jr (1997). Shook over hell: Post-traumatic stress, Vietnam, and the Civil War. Cambridge, MA: Harvard University Press.

Domino, M. L., \& Boccaccini, M. T. (2000). Doubting Thomas: Should family members of victims watch executions? Law and Psychology Review, 24, 59-75.

Dupré, J. (2002). Humans and other animals. Oxford: Oxford University Press.

Esposito, K., Benitez, A., Barza, L., \& Mellman, T. (1999). Evaluation of dream content in combatrelated PTSD. Journal of Traumatic Stress, 12, 681-687.

Foa, E. B., Zinbarg, R., \& Rothbaum, B. O. (1992). Uncontrollability and unpredictability in posttraumatic stress disorder: An animal model. Psychological Bulletin, 112, 218-238.

Frankel, F. H. (1994). The concept of flashbacks in historical perspective. International Journal of Clinical and Experimental Hypnosis, 42, 321-336.

Friedman, M. J., Schneiderman, C. K., West, A. N., \& Corson, J. A. (1986). Measurement of combat exposure, posttraumatic stress disorder, and life stress among Vietnam combat veterans. American Journal of Psychiatry, 143, 537-539.

Hacking, I. (1998). Mad travelers: Reflections on the reality of transient mental illness. Charlottesville, VA: University Press of Virginia.

Hacking, I. (1999). The social construction of what? Cambridge, MA: Harvard University Press.

Harvey, A. G., \& Bryant, R. A. (2000). Memory for acute stress disorder symptoms: A two-year prospective study. Journal of Nervous and Mental Disease, 188, 602-607.

Jones, E., Hodgins-Vermaas, R., McCartney, H., Beech, C., Palmer, I., Hyams, K. et al. (2003). Flashbacks and post-traumatic stress disorder: The genesis of a 20th-century diagnosis. British Journal of Psychiatry, 182, 158-163.

Kardiner, A. (1941). The traumatic neuroses of war. Washington, DC: National Research Council.

Keane, T. M., Zimering, R. T., \& Caddell, J. T. (1985). A behavioral formulation of posttraumatic stress disorder in Vietnam veterans. Behavior Therapist, 8, 9-12.

Kimbrell, T., Myers, M., \& Freeman, T. (2003). Flashbacks and PTSD in US veterans. British Journal of Psychiatry, 183, 263.

Lembcke, J. (1998). The spitting image: Myth, memory, and the legacy of Vietnam. New York: New York University Press.

Lifton, R. J. (1973). Home from the war: Vietnam veterans: neither victims nor executioners. New York: Touchstone.

Lilienfeld, S. O., \& Marino, L. (1995). Mental disorder as a Roschian concept: A critique of Wakefield's "harmful dysfunction" analysis. Journal of Abnormal Psychology, 104, 411-420.

Lipinski, J. F., Jr, \& Pope, H. G., Jr (1994). Do "flashbacks" represent obsessional imagery? Comprehensive Psychiatry, 35, 245-247.

March, J. S. (1993). What constitutes a stressor? The "Criterion A" issue. In J. R. T. Davidson \& E. B. Foa (eds), Posttraumatic stress disorder: DSM-IV and beyond (pp. 36-54). Washington, DC: American Psychiatric Press.

Mayer, P., \& Pope, H. G., Jr (1997). Unusual flashbacks in a Vietnam veteran. American Journal of Psychiatry, 154, 713.

McDonald, J. J., Jr (2003). Posttraumatic stress dishonesty. Employee Relations Law Journal, 28, 93-111. 
McNally, R. J. (2001). On Wakefield's harmful dysfunction analysis of mental disorder. Behaviour Research and Therapy, 39, 309-314.

McNally, R. J. (2003a). Progress and controversy in the study of posttraumatic stress disorder. Annual Review of Psychology, 54, 229-252.

McNally, R. J. (2003b). Remembering trauma. Cambridge, MA: Belknap Press/Harvard University Press.

McNally, R. J. (2004). The science and folklore of traumatic amnesia. Clinical Psychology: Science and Practice, 11, 29-33.

McNally, R. J., Bryant, R. A., \& Ehlers, A. (2003). Does early psychological intervention promote recovery from posttraumatic stress? Psychological Science in the Public Interest, 4, 45-79.

McNally, R. J., Lasko, N. B., Clancy, S. A., Macklin, M. L., Pitman, R. K., \& Orr, S. P. (in press). Psychophysiologic responding during script-driven imagery in people reporting abduction by space aliens. Psychological Science.

Mellman, T. A., David, D., Bustamante, V., Torres, J., \& Fins, A. (2001). Dreams in the acute aftermath of trauma and their relationship to PTSD. Journal of Traumatic Stress, 14, 241-247.

Obermeyer, C. M. (1999). Female genital surgeries: The known, the unknown, and the unknowable. Medical Anthropology Quarterly, 13, 32-39.

Orr, S. P., Metzger, L. J., \& Pitman, R. K. (2002). Psychophysiology of post-traumatic stress disorder. Psychiatric Clinics of North America, 25, 271-293.

Ozer, E. J., Best, S. R., Lipsey, T. L., \& Weiss, D. S. (2003). Predictors of posttraumatic stress disorder and symptoms in adults: A meta-analysis. Psychological Bulletin, 129, 52-73.

Pope, H. G., Jr, Oliva, P. S., \& Hudson, J. I. (1999). Repressed memories: The scientific status. In D. L. Faigman, D. H. Kaye, M. J. Saks, \& J. Sanders (eds), Modern scientific evidence: The law and science of expert testimony (Vol. 1, Pocket Part) (pp. 115-155). St Paul, MN: West Publishing.

Reisner, S. (2003). Trauma: The seductive hypothesis. Journal of the American Psychoanalytic Association, 51, 381-414.

Roemer, L., Litz, B. T., Orsillo, S. M., Ehlich, P. J., \& Friedman, M. J. (1998). Increases in retrospective accounts of war-zone exposure over time: The role of PTSD symptom severity. Journal of Traumatic Stress, 11, 597-605.

Rothbaum, B. O., \& Foa, E. B. (1993). Subtypes of posttraumatic stress disorder and duration of symptoms. In J. R. T. Davidson \& E. B. Foa (eds), Posttraumatic stress disorder: DSM-IV and beyond (pp. 23-35). Washington, DC: American Psychiatric Press.

Rynearson, E. K., \& McCreery, J. M. (1993). Bereavement after homicide: A synergism of trauma and loss. American Journal of Psychiatry, 150, 258-261.

Satel, S. (2003, May 19). The trauma society [Review of the book Remembering Trauma]. New Republic, 228, 29-36.

Schuster, M. A., Stein, B. D., Jaycox, L. H., Collins, R. L., Marshall, G. N., Elliott, M. N. et al. (2001). A national survey of stress reactions after the September 11, 2001, terrorist attacks. New England Journal of Medicine, 345, 1507-1512.

Schwarz, E. D., Kowalski, J. M., \& McNally, R. J. (1993). Malignant memories: Post-traumatic changes in memory in adults after a school shooting. Journal of Traumatic Stress, 6, 545553.

Scott, W. J. (1993). The politics of readjustment: Vietnam veterans since the war. New York: Aldine de Gruyter.

Shephard, B. (2001). A war of nerves: Soldiers and psychiatrists in the twentieth century. Cambridge, MA: Harvard University Press.

Shephard, B. (2002). The rise of the trauma culture. In J. E. Hovens \& G. J. van der Ploeg (eds), De historie van de psychiatrie als basis voor de toekomst (pp. 13-30). Rotterdam: Delta Psychitistrisch Ziekenhuis. 
Shrestha, N. M., Sharma, B., van Ommeren, M., Regmi, S., Makaju, R., Komproe, I. et al. (1998). Impact of torture on refugees displaced within the developing world: Symptomatology among Bhutanese refugees in Nepal. JAMA, 280, 443-448.

Shweder, R. A. (2000). What about "female genital mutilation"? And why understanding culture matters in the first place. Daedalus, 129 (4), 209-232.

Solomon, Z., Kotler, M., Shalev, A., \& Lin, R. (1989). Delayed onset PTSD among Israeli veterans of the 1982 Lebanon War. Psychiatry, 52, 428-436.

Southwick, S. M., Morgan, C. A., III, Nicolaou, A. L., \& Charney, D. S. (1997). Consistency of memory for combat-related traumatic events in veterans of Operation Desert Storm. American Journal of Psychiatry, 154, 173-177.

Summerfield, D. (1999). A critique of seven assumptions behind psychological programmes in war-affected areas. Social Science and Medicine, 48, 1449-1462.

Summerfield, D. (2000). War and mental health: A brief overview. British Medical Journal, 321, 232-235.

Summerfield, D. (2001). The invention of post-traumatic stress disorder and the social usefulness of a psychiatric category. British Medical Journal, 332, 95-98.

van der Kolk, B., Blitz, R., Burr, W., Sherry, S., \& Hartmann, E. (1984). Nightmares and trauma: A comparison of nightmares after combat with lifelong nightmares in veterans. American Journal of Psychiatry, 141, 187-190.

van der Kolk, B., Greenberg, M., Boyd, H., \& Krystal, J. (1985). Inescapable shock, neurotransmitters, and addiction to trauma: Toward a psychobiology of posttraumatic stress. Biological Psychiatry, 20, 314-325.

Wakefield, J. C. (1992). The concept of mental disorder: On the boundary between biological facts and social values. American Psychologist, 47, 373-388.

Wakefield, J. C., \& Spitzer, R. L. (2002). Lowered estimates-but of what? Archives of General Psychiatry, 59, 129-130.

Wilson, R. A. (ed.). (1999). Species: New interdisciplinary essays. Cambridge, MA: MIT Press.

Yehuda, R., \& McFarlane, A. C. (1997). Introduction. In R. Yehuda \& A. C. McFarlane (eds), Psychobiology of posttraumatic stress disorder (pp. xi-xv). New York: New York Academy of Sciences.

Young, A. (1995). The harmony of illusions: Inventing post-traumatic stress disorder. Princeton, NJ: Princeton University Press.

Young, A. (2001). Our traumatic neurosis and its brain. Science in Context, 14, 661-683.

Young, A. (2002). The self-traumatized perpetrator as a "transient mental illness." L'Evolution Psychiatrique, 67, 630-650. 